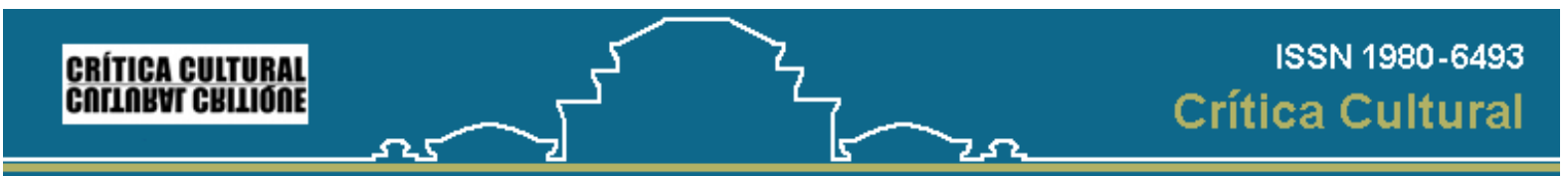

Crítica Cultural, volume 3, número 1, jan.jjun. 2008

\title{
ABAIXO O DEDO DE DEUS E OS NÚMEROS REDONDOS: PERFORMANCE SURREALISTA E ESCRITURA DO PRESENTE
}

Rita Lenira de Freitas Bittencourt-

Resumo: 0 francês Antonin Artaud, poeta, ator, roteirista e diretor de teatro, segundo o escritor espanhol Enrique Vila-Matas, completaria 99 anos em 4 de dezembro de 1995, sendo o primeiro "resgatado" em artigo, na coluna dominical do Diário 16, de Madri. Compõe com outros 51 textos-nomes, num pretenso avesso das homenagens, um mosaico de referências que é posteriormente transformado em livro: Para acabar con los números redondos, 1997. Na proposta jornalística inicial, de subverter datas e cânones, o que se destaca em Vila-Matas é o gesto performático e anacrônico de evocar uma potência política a partir de suporte alternativo e de cruzamentos an-estéticos com o surrealismo, permitindo ler a poética do presente em suas múltiplas relações disjuntivas.

Palavras-chave: poéticas do presente, Vila-Matas, Artaud, Surrealismo, vanguardas.

No limite, aquele que fala confessa a sua impotência.

Bataille, 0 erotismo.

\section{Vila-Matas e a ditadura dos números redondos}

Antonin Artaud, segundo o escritor espanhol Enrique Vila Matas, completaria 99 anos em 4 de setembro de 1995, sendo o primeiro dentre os "resgatados" em artigo, na sua coluna dominical, no Diário 16, de Madri. Vila-Matas, por sua vez, completaria 50 anos nesta época, e este é o principal motivo por sua aversão, finalmente externada, aos números redondos, em glosa a um título -"Para acabar com o julgamento de Deus $[1]$ "- do teatrólogo francês. "Me irrita de ellos, sobre todo, su injustificado y absurdo prestigio. No veo por qué el número 100 tiene más relevancia que el 101, por ejemplo $\underline{[2]}$ ", escreve o criador de "Bartleby e Cia", para, em seguida, fazer uma espécie de anamnese desta perturbação tão incomum:

\begin{abstract}
El origen de mi odio inmenso a los números redondos es posible que se encuentre en esos aburridos monográficos de los suplementos literarios dedicados - de vez en cuando y muchas veces sin previo aviso - a celebrar, con números redondos, aniversarios de literatos. Soy un fanático de los suplementos literarios porque suelo encontrar en ellos referencias o escritos inéditos sobre mis autores preferidos. Pero la moda de celebrar en esos suplementos los 20,50, 100, 500 aniversario del nacimiento o muerte de un literato normalmente logra sacarme de quicio, pues arruina - casi siempre la figura conmemorada que ocupa de repente todo el suplemento no es santo de mi devoción - mis expectativas de leer frases nuevas sobre mis escritores favoritos. Y es que por una figura conmemorada que me interesa suele haber unas 27 que me aburren profundamente y que, encima, me impiden de leer nuevas ocurrencias sobre las figuras literarias que realmente me interesan $\underline{[3]}$
\end{abstract}

Neste Prólogo, que acompanha a compilação dos artigos, dois anos mais tarde, no livro Para acabar con los números redondos, VilaMatas adjetiva de "criminosos" os suplementos que o levaram a desenvolver um "ódio terrível" a estes números, um ódio quase inconsciente enfim manifesto na data exata de 3 de setembro, às vésperas do aniversário de Artaud, e que vai inaugurar uma série de escritos curiosos sobre escritores, em uma coluna jornalística de opinião, até então muito mal resolvida.

Inicialmente, o escritor pensara em utilizar a coluna para escrever sobre as vicissitudes da política espanhola e, diante do fracasso, dos inúmeros problemas e das críticas daí decorrentes, passara a tecer ácidos comentários sobre os programas de TV, o que só o deixou ainda mais insatisfeito, por considerar que esta é uma das mais medíocres alternativas que restam a um crítico. Até que, em setembro, com Artaud, Ihe veio a idéia de literaturizar o espaço, o que o deixou feliz pela primeira vez, ainda mais que o seu problema com deus, os números redondos, tornou-se o mote, o eixo central da coluna.

No sentido utilizado por Deleuze, a literatura, na prática vila-matasiana, torna-se, desde então, um exercício de cura. E, previsivelmente, o colunista, movido pela combinação entre surrealismo dissidente, a loucura de Artaud e suas próprias excentricidades, ao longo de mais ou menos um ano, todas as semanas, vai desfiando um longo rosário de "santos de sua devoção", tomando sempre o cuidado para que as datas comemorativas dos aniversários de nascimento não fossem, jamais, registradas nos tais números redondos.

0 primeiro artigo "Nivelador del periplo imbécil", previsivelmente dedicado a Artaud, compõe, então, com outros 51 textos-nomes, um pretenso avesso das homenagens, um mosaico de referências: os 252 anos de nascimento de Laurence Sterne são registrados em "La sociedad de la alegría", os 104 anos de Pedro Salinas recebem o título de "Cementerio contemplado", em um texto que homenageia, também, Porto Rico e, por extensão, Juan Ramón Jiménez. Lêem-se os 108 anos de Fernando Pessoa no artigo "Nos abrigamos mal" e ainda os 105, de Álvaro de Campos, num texto em que a sua aparência física é explorada: "El hombre que se parecía a Pessoa", e por aí vai, encerrando com uma anedota sobre Borges, em seu $98^{\circ}$ aniversário, que rememora uma situação improvável, num encontro com Victoria Ocampo, quando ambos eram ainda jovens e desconhecidos, e, por isso mesmo, capazes de todos os disfarces: "Una peluca en Mar del Plata".

Na proposta jornalística inicial, de subverter datas e cânones, o que se destaca na teia vila-matasiana é o gesto performático e anacrônico de evocar uma potência política do presente a partir de suporte alternativo - pois trata-se de um semanário, com seus textos marginais e sua heterogeneidade discursiva - unido à proposta de cruzamentos an-estéticos com as vanguardas - partindo da tensão Artaud/Deus ou Artaud/Breton -, que permite ler a criação poética em múltiplas relações disjuntivas: em uma abordagem bem humorada que propõe questões sérias, simultaneamente reverente e crítica às homenagens; em uma espécie de retorno inevitável aos nomes de certa mística pessoal acompanhado de uma condenação explícita às idealizações da autoria.

0 trabalho muda de categoria, passando de coluna a livro, na medida em que uma crise econômica atinge o jornal, que, cada vez mais, passa a vender menos. Ultimo sobreviviente de un desastre, Vila-Matas relata: "Llegó un domingo 23 de junio del 96, en que me ocupe de Lichtemberg, y lo hice con la moral ya muy baja, pues resulta muy penoso escribir para un periódico sabiendo que nunca te pagarán y que, además, nadie va a leerte. Mi actividad de columnista se había convertido en una práctica kafkiana del periodismo $\underline{\text { [4] }}$. 0 derradeiro artigo, intitulado "Entonces, cuando el alma era inmortal", comemorando os 254 anos do filósofo e escritor alemão, descreve a estranha atmosfera da Alemanha pré-romântica:

“la vida en Alemania se regía por un severo código de las supersticiones. Los cuervos, los búhos, las cornejas, las urracas y la madera apolillada eran signos de mal agüero; los campesinos hacían ofrendas de huevo e manteca; el aullido de los perros presagiaba la muerte; corrían leyendas de dragones que salían de las chimeneas, colonias de ratas, homúnculos asesinos, lluvias de leche y sangre. La gente del palacio, aparte de sucia, no era menos supersticiosa: un cristal de bohemia resquebrajado, el crujido de un arma colgada en la pared, un reloj adelantado o atrasado eran señales clarísimas del desastre./ Y en eso llegó Lichtenberg./ No 
llegó, por supuesto, solo. (...) Ese país tan bestia se convirtió de pronto en la patria del romanticismo, del racionalismo, del clasicismo y de la filosofía kantiana, de Goethe, de Beethoven, de Fichte, de Schiller y Hölderlin. Ningún retrógrado se cruzo en su camino. (...) Fue el último de los diecisiete hijos del pastor Johan Conrad Lichtenberg y de su mujer, Henriette Catharina. Casi todos los hijos se morían al nacer, y Lichtenberg, que fue el último en hacerlo en esa familia, se inventó un modo de sobrevivir a costa de quedarse pata toda la vida enano y jorobado. / Dentro de ocho días, sus fervorosos partidarios celebraremos ese aniversario de su heroico nacimiento y sobrevivencia. Y lo haremos recordando algunas de sus frases de jorobado que se reía de la manera más infinitamente seria: 'Entonces, cuando el alma aún era inmortal', 'La característica principal de la verdadera libertad y de su verdadera práctica es el abuso que se hace de ellas', 'Daría parte de mi vida con tal de saber cuál era la temperatura media en el paraíso, [5]."

0 projeto do livro concretizou-se com o acréscimo de nove textos, um ano depois. E responde a uma brincadeira do amigo Ricardo

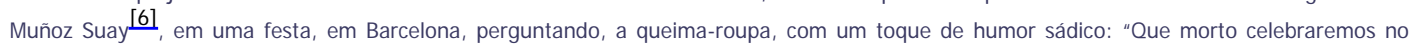
próximo domingo?".

Neste momento, segundo o Prólogo, Vila-Matas percebe que sua atividade na coluna tinha certo parentesco com os obituários: o que, afinal, ele elaborava nada mais era que uma lista de mortos e, portanto, pela absoluta nulidade desta função - já que escrever obituários é uma espécie de punição que se prescreve aos jornalistas, não havendo atividade considerada pior em uma redação -, ela devia configurar um livro.

Usando de um estratagema, quando comemora os 80 anos de Roland Barthes, no texto "Pensadores de café frío", o colunista faz com que se publique, como se fosse redigida por alguém do jornal, antes do título, a seguinte chamada:

“Desde hace 11 semanas, en su columna dominical de este periódico, Enrique Vila-Matas se dedica a celebrar aniversarios de nacimiento de escritores, aniversarios poco ortodoxos, ya que las cifras nunca coinciden con números redondos. El péndulo caótico podría ser el título secreto de esta columna dominical, el título también de un posible futuro libro, siempre y cuando Vila-Matas, tal como se ha propuesto, alcance un mínimo de 52 columnas, 52 semanas, un año completo que algún día celebraremos todos $\underline{\text { [7] }}$."

Não por acaso, as primeiras frases da homenagem a Barthes são assombradas por outra morte: "Con el vuelo mortal de Gilles Deleuze, con su patético suicidio de la semana pasada (...) ya no queda vivo ninguno de los pensadores que tanto marcaron mi primera juventud ${ }^{[8]}$ ". E na performance de falsificação de sua própria lavra e punho, o escritor obtém, como se viesse da esfera administrativa da redação, uma licença, a validação pública e publicada do livro por vir.

0 pêndulo caótico marca, na superfície enlouquecida do tempo, as palavras da falta, inclui mais um na lista dos mortos, e, para continuar acabando com o julgamento de deus, forja a licença para publicá-las, mesmo que não sirvam para coisa alguma.

\title{
2. Artaud e o divino juízo
}

"Para Acabar com o Julgamento de Deus", um dos textos mais conhecidos e estudados, de Antonin Artaud, tem sido disponibilizado na internet, na íntegra ou em excertos, em português, francês, espanhol e inglês, em versões escritas ou auditivas, numa proliferação, tardia e tagarela, que resgata o gesto de 1947, quando o artista gravou, para o programa "A voz dos poetas" da rede francesa, esta peça radiofônica [9], escrita em versos, que acabou nem indo ao ar, na data prevista, por motivo de censura. Ironicamente, Artaud, morreria alguns meses depois sem chegar a ouvi-la, e a audição se dará somente na década de 70.

O texto inicia-se com o "Rito de sol negro", que vai ser desdobrado no poema seguinte "A busca da fecalidade", encerrando o primeiro movimento e operando por clivagens, destinadas a escavar o espaço, a preparar a emergência de um outro, alternativo ao ego, um todo-Outro que pode ser chamado Deus, Cristo, ou corporificar qualquer instância autoritária, de pensamento e de linguagem: a revolução, Hitler, o PC francês, a guerra ou o próprio líder do movimento surrealista. Um todo-Outro que precisa ser evocado e exposto para ser, finalmente, destruído.

De início, Artaud monta um caminho, que é uma escolha: o Tutuguri, o rito de abolição da cruz, inspirado no contato com os índios mexicanos, Tarahumaras, e nas suas experiências com o peiote. Ao som do tambor, evoca a baba da mãe primordial, um círculo de seis cruzes incrustadas em uma terra seca, imunda e escura, "no pé da encosta amarga, cruelmente desesperada do coração", e seis homens, que se metamorfoseiam em animais e plantas, um para cada sol. Enquanto o sétimo, que é também cavalo, chega a galope, a toda a velocidade:

\author{
ultimo sol \\ o primeiro homem \\ o cavalo negro com um \\ homem nu \\ absolutamente nu \\ e virgem \\ em cima ${ }^{[10]}$
}

O tom maior deste ritual se dá quando os homens, sob o comando do cavalo-cavaleiro, arrancam, em movimentos giratórios, as seis cruzes cravadas no chão. A expressão "a abolição da cruz" aparece em destaque, em maiúsculas, nos versos finais do poema, que acaba em sangue, numa imagem que superpõe o cavalo, uma enorme ferradura e o gesto de uma punhalada.

Procede-se, então, um mergulho nos excrementos. o segundo poema considera o dejeto, o resto, a sobra, "algo particularmente tentador para o homem/ algo que vem a ser justamente/ O COCÔ". Destaco no texto este "o cocô" - "Le caca" em francês, "La caca", em espanhol - escrito em maiúsculas e com a indicação, entre parênteses "(aqui rugido)" que se torna ainda mais visível, em verso separado, e tem a sua primeira emergência sonora acompanhada de um efeito especial, marcando, na performance oral e também na escrita, um retorno à animalidade e ao prazer sofisticado do abjeto:

Então o homem recuou e fugiu.

E então os animais o devoraram.

Não foi uma violação,

ele prestou-se ao obsceno repasto.

Ele gostou disso

e também aprendeu

a agir como animal

e a comer seu rato

delicadamente.

Só a fecalidade é humana, formadora e igualitária: "onde fede a merda, fede a ser", sentencia o poema, e a carne é merda, os ossos são merda, e deus, obviamente, também será merda, porque, se não for, esta é a prova cabal de sua inexistência e de sua vacuidade:

Ora, ele não existe

a não ser como vazio que avança com todas as suas formas

cuja mais perfeita imagem

é o avanço de um incalculável número de piolhos.

"O Sr. está louco, Sr. Artaud? E então a missa?"

Eu renego o batismo e a missa.

Não existe ato humano 
no plano erótico interno

que seja mais pernicioso que a descida

do pretenso jesus-cristo

nos altares.

Ninguém me acredita

e posso ver o público dando de ombros

mas este tal cristo é aquele que

diante do percevejo deus

aceitou viver sem corpo

As provas do corpo, carne e ossos, suas secreções, sangue, fezes, suor, urina e mesmo os gases, desafiam, com sua materialidade absoluta e finita, o invisível e implacável julgamento de deus. As glossolalias $\frac{[11]}{2}$ nada mais fazem do que estender esta materialidade radical do humano ao cerne da linguagem:
reche modo
to edire
de za
tau dari
do padera coco

Em relação aos desenhos de Artaud, Jacques Derrida refere-se a pictografias, literalmente pinturas cujas sentenças se deixam escutar no momento em que as descrições ficam fora de controle, ultrapassam os seus limites, ou renunciam mesmo a um sentido. Artaud nos faria escutar as glossolalias resultantes de uma violência que força a língua a um retorno, a um dobra-se sobre si mesma:

$$
\begin{aligned}
& \text { Letras transcrevem fonemas que não pertenceriam a nenhuma língua "natural"; forçam a chamada língua } \\
& \text { natural a voltar, como se ficasse louca, a um estado anterior a seu nascimento, ao in-ato da proposição, da } \\
& \text { frase proposicional e representativa, da cópula interposta entre o -jeto do objeto e -jeto de sujeito } \underline{[12]}
\end{aligned}
$$

Neste corpo-a-corpo que Artaud realiza com a língua e também com a plástica, define-se um fundo sem fundo no qual a palavra, o som, a imagem se sustentam como um corpo, um subjéctil maleável, que permite variações, em operações de mão-dupla nas quais suporta 0 prazer e a crueldade. Para o teórico argelino, o teatro e a literatura são as "frases" de uma sintaxe performativa, que quando se torna glossolalia invoca uma competência de entonação que nunca se cristaliza, ou seja, encena o subjéctil mesmo posto em drama.

Em outro texto, "A inabilidade sexual de Deus", a relação com o desenho é também posta em música. É entonação, projeção no espaço e hieróglifo:

$$
\begin{aligned}
& \text { yo kutemar tonu tardiktra } \\
& \text { yo kute diktra anu tedri[13] }
\end{aligned}
$$

O que dizem as palavras, o dizem em face de um sentir, de um sofrer que é físico-gráfico, e que se acoplam, espaço e letra, como entonações sólidas no ar, segundo Derrida. São concretas apenas aquelas que, gases, fezes, sons, sopros, saliva ou esperma, saem do corpo, espontaneamente ou por pressão, constrangimento:

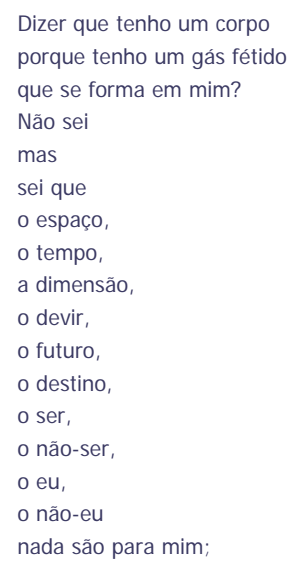

Essas variações sobre o corpo, no entanto, ao acabarem com o julgamento de Deus, redesenham o corpo do outro lado, o do infinito e da falta: "Parece que a consciência / está ligada/ em nós/ ao desejo sexual / e à fome", afirmam os versos de "A questão que se coloca...". E ultrapassam a própria materialidade: Quando da apresentação do corpo como nome, trata-se do corpo pressionado contra o próprio corpo, 0 que resulta em um corpo sem fim, no qual, segundo um dos versos "não se toca nunca", ou ainda: "O corpo é uma multidão excitada, uma espécie de caixa de fundo falso que nunca mais acaba de revelar o que tem dentro. E tem dentro toda a realidade $\underline{[14]}$."

o poema final, suplementar, intitulado "post scriptum", encena a duplicação do corpo que é outro, que se sabe o todo-Outro desenhado no limite, traçado no fim de Deus:

\author{
Quem sou eu? \\ De onde venho? \\ Sou Antonin Artaud \\ E basta dizê-lo \\ Como só eu sei dizer \\ E imediatamente \\ Verão meu corpo atual \\ Voar em pedaços \\ e se juntar \\ sob dez mil aspectos \\ notórios \\ em um novo corpo \\ no qual nunca mais \\ poderão \\ me esquecer.
}


O corpo apresentado como nome, que é singular e irrepetível: "Sou Antonin Artaud / Como só eu sei dizer", ou em outro lugar, o mesmo e diferido: "Eu sou Antonin Artaud, eu sou meu filho, meu pai, minha mãe e eu mesmo", desmancha-se, em sua dimensão contingente, temporal, e se recria novo, puro osso, esqueleto eterno, definitivo em sua materialidade e inesquecível pela ultrapassagem, em direção ao corpo sem órgãos, enfim, conquistado. Seja qual for o nome que tenha: intensidade, poesia, abismo de sentidos, loucura. Ou, mais modestamente, programa de rádio.

\section{Performance surrealista e escritura do presente}

Se Artaud afirmava escutar os pintores, se era capaz de desenhar com a boca ou de tingir a vida com sangue, delicadamente, é porque aplicava a si, ou melhor, padecia, sofria de uma ética da crueldade que, em suas produções, tornou-se uma ética do rigor absoluto. No fim do alto modernismo, no declínio das vanguardas, o artista francês forja, definitivamente, a ferro e fogo, com o seu corpo e sua revolta, um

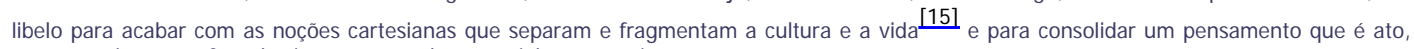
que se projeta para fora de si mesmo, sendo potencialmente perigoso.

Em Artaud, retomando Foucault, "a linguagem é recusada como discurso e retomada na violência plástica do choque, remetida ao grito, ao corpo torturado, à materialidade do pensamento, à carne $\underline{[16]}$.

No artigo que Ihe dedica Vila-Matas, a cena final é a de um gesto, enviado pelo artista, desde o além-texto, aos que se apressaram, após a sua morte, a lê-lo como um excêntrico, ou como um gênio, ou como um louco:

Desde su nuevo infierno, Artaud debió responderles con un gesto habitual en él, un gesto no desprovisto de

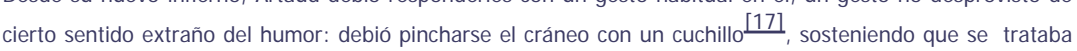
de su método de lucha contra los espíritus malhechores, que le perseguían incesantemente $\underline{[18]}$.

Interessa ao escritor espanhol a cifra do gesto-enigma que, ao encenar um intermitente ferir-se resgata uma posta em ato que é, ainda, pulsante, mediante uma escritura não apenas da morte de deus, mas de seu interminável assassinato: para continuar a acabar com os maus espíritos; com as obras-primas; com a superstição social da família; com o teatro burguês; com a ditadura do sentido; com a cronologia do tempo histórico.

Ao entabular com uma série de literatos mortos outra série de conversas íntimas, cheias de detalhes pitorescos e triviais, a compilação vila-matasiana ensaia, com eles, esta montagem que também é corpo e texto, - Artaud sobrevive 52 anos, de 1896 a 1948 , e VilaMatas compõe o seu livro como um enorme corpo monstruoso, segmentado em 52 artigos, ou em 52 cabeças, cada qual com um, dois ou mais nomes -, e o exercita nas margens, pois, de certo modo, os textos escritos para jornal são os dejetos do campo de produção midiática, e sofrem os efeitos desta condição descartável que os tornam letra duplamente morta nas manhãs de segunda-feira.

A sobrevida, em livro, marca um retorno aos fantasmas, a um tempo da literatura que é espectro, retificação não cronológica, não sucessiva, dela mesma. Na escritura do presente, o tempo, que, desde Shakespeare, está fora dos gonzos, conforme Deleuze, "deixa de estar curvado por um Deus que o faz depender do movimento, deixa de ser cardinal e se torma ordinal.(...) Nem cósmico, nem rural, torna-se o tempo da cidade e nada mais, a pura ordem do tempo $\underline{[19]}$

Os eventos performáticos restauram o tempo moderno da crise, e o re-instauram na crítica, espetacularizando um vazio que sofre e fala, uma palavra que tem cores e arestas e cifras que não são redondas.

\section{Referências:}

BLANCHOT, Maurice. O livro por vir. Trad. Leyla Perrone-Moisés. São Paulo: Martins Fontes, 2005.

BRAUNE, Fernando. O surrealismo e a estética fotográfica. Rio de Janeiro: 7 Letras, 2000.

DELEUZE, Gilles. Crítica e clínica. Trad. Peter Pál Pelbart. São Paulo: 32, 1997.

Mil Platôs. Capitalismo e esquizofrenia. Vol. 3. Trad. Aurélio Guerra neto, Ana Lúcia de Oliveira, Lúcia Cláudia Leão e Suely Rolnik. São Paulo: 34, 1995.

DERRIDA, Jacques. A escritura e a Diferença. 2a. ed. Trad. Maria Beatriz M. Nizza da Silva. São Paulo: Perspectiva, 1995.

. Posições. Trad. Tomaz Tadeu da Silva. Belo Horizonte: Autêntica, 2001.

. e Norma Bergstein,. Enlouquecer o subjétil. Trad. Geraldo Gerson de Souza. São Paulo: Ateliê Editorial Ltda, 1998.

FÉLíCIO, Vera Lúcia. A procura da lucidez em Artaud. São Paulo: Perspectiva, 1996.

FOUCAULT, Michel. História da sexualidade 2: o uso dos prazeres. Trad. Maria Thereza da Costa Albuquerque. Rio de Janeiro: Graal, 1984.

As palavras e as coisas. Trad. Salma Tannus Muchar. São Paulo: Martins Fontes, 2002.

GA-T̄ENO Alex. Antonin Artaud. A revolta de um anjo terrível. Porto Alegre: Editora Sulina, 2005.

VILA-MATAS, Enrique. Para acabar con los números redondos. Valencia: Pre-textos, 1997.

VIRMAUX, Alain. Artaud e o teatro. Trad. Carlos Eugênio Marcondes Moura. São Paulo: Perspectiva, 2000.

WILLER, Cláudio. Escritos de Antonin Artaud. Porto Alegre: L\&PM, 1983.

Recebido em 08/ 05/ 2008. Aprovado em 10/ 06/ 2008.

Title: Down with the Finger of God and Round Numbers: Surrealist Performance and Writing of the Present

Author: Rita Lenira de Freitas Bittencourt

Abstract: According to the Spanish writer Enrique Vila-Matas, Antonin Artaud, the French poet, script writer, actor, and stage director would be 99 years old on December 4, 1995, becoming the first one "redeemed", in an article in the Sunday column of the Diário 16, from Madrid. Together with other 51 texts-names, it comprises, as a supposed reverse of the homage, a mosaic of references that is later transformed into a book: Para acabar con los números redondos, 1997. In the initial journalistic project of subverting dates and the canon, what stands out in Vila-Matas is the anachronic and performative gesture of evoking a political potency from an alternative medium and from anesthetic crossings with surrealism, making way to read the poetics of the present in its multiple disjunctive relations.

Keywords: poetics of the present, Vila-Matas, Artaud, Surrealism, Vanguards

Tìtre: Dehors le Doigt de Dieu et les Nombres Ronds: Performance Surréaliste et Écriture du Présent

Auteur: Rita Lenira de Freitas Bittencourt

Résumé: Le français Antonin Artaud, poète, acteur, scénariste et metteur-en-scène de théâtre, selon l'écrivain espagnol Enrique Vila-Matas, aurait 99 ans le 4 Décembre 1995, étant le premier à être "racheté", dans un article, dans la rubrique de dimanche du Diário 16, de Madrid. II compose, au-delà de 51 textes-noms, dans un soi-disant peu disposé aux hommages, un mosaïque de références qui est par la suite transformé en livre: Pour en finir avec les nombres ronds, 1997. Dans la proposition journalistique du début, celle de renverser des dates et canons, ce qui se détache chez Vila-Matas c'est le geste performatique et anachronique de susciter une puissance politique à partir d'un support alternatif et des croisements inesthétiques avec le surréalisme, permettant lire la poétique du présent dans ses multiples rapports disjonctifs.

Mots-clés: Poétiques du présent, Vila-Matas, Artaud, Surréalisme, Avant-garde

Título: Abajo el Dedo de Dios y los Números Redondos: Performance Surrealista y Escritura del Presente

Autor: Rita Lenira de Freitas Bittencourt

Resumen: El francés Antonin Artaud, poeta, actor, guionista y director de teatro, según el escritor español Enrique VilaMatas, completaría 99 años el 4 de diciembre de 1995, siendo el primer "rescatado", en artículo, en la columna dominical del Diario 16, de Madrid. Compone, con otros 51 textos-nombres, en un pretenso contra los homenajes, un mosaico de referencias que es posteriormente transformado en libro: Para acabar con los números redondos, 1997. En la propuesta periodística inicial, de subvertir fechas y cánones, lo que se destaca en Vila-Matas es el gesto desempañado y anacrónico de evocar una potencia política a partir de soporte alternativo y de cruces an-estéticos con el surrealismo, permitiendo leer la poética del presente en sus múltiples relaciones disyuntivas.

Palabras-clave: Poéticas del presente, Vila-Matas, Artaud, Surrealismo, Vanguardias 
* Doutora em Teoria Literária e Literatura Comparada.

[1] Pour en finir avec le jugement de dieu, no original. Cito, neste ensaio, duas versões traduzidas para o português: a de Cláudio Willer (1983), e outra, retirada da internet: http://www.alol.com.br/acesso/outros/

[2] Cf. VILA-MATAS, Enrique. "Prólogo". In. Para acabar con los números redondos. Valencia: Pré-textos, 1997, p. 7.

[3] Idem, ibidem.

[4] Idem, ibidem.

[5] Op. Cit., pp. 97 e 98

[6] O escritor aproveita para fazer uma homenagem, não sem um toque de ironia, a Ricardo Muñoz Suay (Valencia, 1917-1997), roteirista, produtor e crítico do cinema espanhol, preso durante a ditadura e membro do PC até a década de 70. A coletânea de artigos de Vila-Matas é publicada no mesmo ano da morte do cineasta.

[7] Op. Cit., p. 9.

[8] Op. Cit, p. 33

[9] Reprodução em áudio, a peça radiofônica Para acabar de vez com o julgamento de Deus, de Antonin Artaud foi gravada por Artaud - entre 22 e 29 de novembro de 1947- a convite de Fernand Pouey, diretor dos programas dramáticos e literários da Radiodifusão Francesa (R.D.F.) e responsável pelo programa "A voz dos poetas". Com Roger Blin, Maria Casarès, Paule Thévenin e Antonin Artaud. Apresentação de Roger Vitrac.

[10] ARTAUD, Antonin. Para acabar com o juízo de Deus. In. WILLER, Cláudio. Escritos de Antonin Artaud. Porto Alegre: L\&PM, 1983, p.153.

[11] Derrida define assim a glossolalia: “...um monte de palavras possíveis [que] fervilham sob a superfície, prontas a emprenhar ou a reprimir a chamada língua natural para livrar-se dela" e refere-se, ainda à "glossolalia dos profetas [que] supostamente 'falava em línguas'; afirmava-se que era imediatamente acessível aos sujeitos de línguas diferentes, universalmente inteligível antes de qualquer tradução, como se supõe por ingenuidade da pintura ou do desenho." Cfe. Enlouquecer o subjéctil, op. Cit., p. 52.

[12] Cf. DERRIDA, Jaques. Enlouquecer o subjétil. P. 48.

[13] Citado por Derrida, op. Cit, p.53.

[14] ARTAUD, Antonin. História vivida de Artaud - Momo. Portugal: Hiena, 1995, p.78. Apud. GALENO, Alex, op. Cit., pp. 144-145.

[15] Cfe. GALENO, Alex. Op. Cit., p.18.

[16] FOUCAULT, Michel. As palavras e as coisas, p.531.

[17] Na frase "debió pincharse el cráneo con un cutillo" destaco e mantenho em aberto o sentido vário de "pinchar": picar, ferir com objeto pontiagudo, perfurar, furar e, também, estimular.

[18] VILA-MATAS, Enrique. "Nivelador del periplo imbecil. / Antonin Artaud". Op, cit., p. 12

$\underline{\text { [19] }}$ Cfe. DELEUZE, Gilles. "Sobre quatro fórmulas poéticas que poderiam resumir a filosofia kantiana”. In. Crítica e Clínica, p.37.

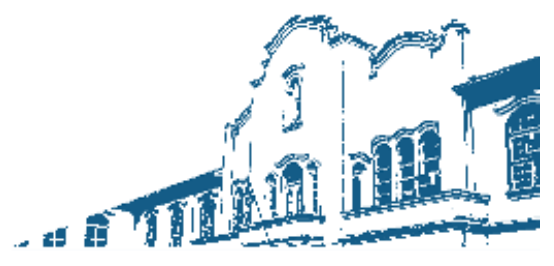

Copyright PPGCL/ Unisul 2006 @ (48) 3621-3369 - Desenvolvimento: Prof. Dr. Fábio J osé Rauen 